\title{
Modelos mentais como condicionantes do pensamento estratégico: estudo no poder judiciário do estado de Rondônia
}

\author{
Ione Grace do Nascimento Cidade ${ }^{1}$ \\ José Moreira da Silva Neto \\ Jorge Luiz Coimbra de Oliveira ${ }^{3}$ \\ Maria Berenice Alho da Costa Tourinho ${ }^{4}$ \\ Jacqueline Baptista de Souza Lima ${ }^{5}$
}

\section{Resumo}

O objetivo deste estudo foi verificar como os modelos mentais podem condicionar o pensamento estratégico na consecução das estratégias estabelecidas no Plano Estratégico do Poder Judiciário de Rondônia - PJRO, que busca melhorar a qualidade dos serviços prestados pelo Judiciário. A metodologia utilizada foi o estudo de caso, com delineamento do tipo exploratório e descritivo, considerando-se a abordagem qualitativa. A abordagem do estudo sobre modelos mentais foi feita na perspectiva de Johnson-Laird, que propõe os modelos mentais como mediadores das relações entre o sujeito e o mundo que o cerca; enquanto a abordagem sobre planejamento estratégico foi feita sob a perspectiva de Mintzberg, com o enfoque na Escola da Aprendizagem, buscando compreender o planejamento estratégico voltado para uma organização viva onde os sujeitos devem pensar estrategicamente. Este estudo verificou que persiste no PJRO a tomada de decisão baseada na perspectiva de modelos mentais estabelecidos em experiências pessoais adquiridas no trabalho, desfavoráveis ao aparecimento do pensamento estratégico.

Palavras-chave: Modelos mentais. Pensamento estratégico. Poder judiciário.

\footnotetext{
1 Mestra em Administração pela Universidade Federal de Rondônia.

Doutor, Professor da Universidade Federal de Rondônia.

Doutor, Professor da Universidade Federal de Rondônia.

${ }^{4}$ Doutora, Professor da Universidade Federal de Rondônia.

5 Mestranda em Administração pela Universidade Federal de Rondônia.
} 


\section{Introdução}

O Poder Judiciário do estado de Rondônia implementou no final de 2007 o seu primeiro planejamento estratégico, revisado em 2009 com vistas a melhorar a prestação dos serviços jurisdicionais à sociedade, e contribuir para a evolução do estado e de seu relevante papel na conduta de políticas públicas sociais mais eficazes.

No entanto, como afirma Peter Senge (2008, p. 42), os modelos mentais são "pressupostos profundamente arraigados, generalizações ou mesmo imagens que influenciam nossa forma de ver o mundo e de agir", fazendo com que as estratégias pretendidas nem sempre sejam realizadas. Dessa forma, busca-se responder à seguinte questão: como os modelos mentais dos gestores podem estar desalinhados aos propósitos declarados, desejados e inerentes ao planejamento estratégico da organização?

Este artigo tem como objetivo geral avaliar o comprometimento dos gestores na consecução das estratégias estabelecidas no Planejamento Estratégico do Poder Judiciário do estado de Rondônia e, como objetivos específicos: conhecer aspectos de sua formulação, objetivos, visão e missão; avaliar a comunicação existente no alcance dos objetivos do planejamento estratégico, avaliar o envolvimento dos gestores nas atividades de planejamento estratégico e conhecer qual o percentual de alinhamento entre o planejamento estratégico e a sua execução prática na organização.

A abordagem do estudo sobre modelos mentais foi feita na perspectiva de Johnson-Laird, que propõe os modelos mentais como mediadores das relações entre o sujeito e o mundo que o cerca, apresentando-se como fator de restrição para as suas construções, que podem influenciar na capacidade dos sujeitos de resolver situações-problemas cotidianas; enquanto a abordagem sobre planejamento estratégico foi feita sob a perspectiva de Mintzberg, com o enfoque na Escola da Aprendizagem, buscando-se compreender o planejamento estratégico voltado para uma organização viva onde o estrategista deve estar atento às visões de curto e longo prazo, sob uma perspectiva evolutiva em que as mudanças ocorrem muito rapidamente e de forma imprevisível. 
Para a definição quanto à forma de abordagem do problema investigado, considerou-se a afirmação de Creswell (2007, p. 38), ao dizer que "se um conceito ou fenômeno precisa ser entendido pelo fato de ter sido feita pouca pesquisa sobre ele, então é melhor uma técnica qualitativa", acrescentando que a "pesquisa qualitativa é exploratória e útil quando o pesquisador não conhece as variáveis importantes a examinar [...] porque nunca foi abordada com uma determinada amostra ou grupos em estudo". Essa é a situação que se apresentou em relação ao Planejamento Estratégico no Poder Judiciário de Rondônia, justificando-se, portanto, a utilização da pesquisa qualitativa no desenvolvimento deste estudo que buscou verificar: como os modelos mentais dos gestores podem estar desalinhados aos propósitos declarados, desejados e inerentes ao planejamento estratégico da organização.

Esta pesquisa tem um delineamento do tipo levantamento que, segundo Creswell (2007, p. 161), "dá uma descrição quantitativa ou numérica de tendências, atitudes ou opiniões de população". Também pode ser considerada como exploratória e descritiva porque buscou proporcionar maior familiaridade com o problema e descrever as características peculiares de determinado grupo de pessoas.

A população, constituída de dez gestores responsáveis pelas unidades coordenadoras das ações estratégicas definidas no Plano Estratégico, correspondeu a amostra deste estudo de caso.

Os dados secundários foram coletados de fontes, como Planejamento Estratégico do PJRO e Plano de Operacionalização do PE/PJRO, constantes nos arquivos da Coordenadoria de Modernização e Gestão Estratégica do Poder Judiciário do estado de Rondônia; enquanto os dados primários foram coletados por meio da aplicação direta aos participantes, de questionário com perguntas fechadas e uma questão aberta. O questionário aplicado aos gestores da organização foi composto por perguntas que obedeceram a um critério em escala de cinco possibilidades que representavam a opinião sobre uma afirmação, além de uma pergunta aberta ao final. A escala teve o princípio de funcionamento de uma balança tipo gangorra, na qual a opinião apresenta-se como um peso que a equilibra (indiferente) ou desequilibra para algum dos lados (discordando ou concordando). 


\section{Base teórica}

\subsection{Modelos mentais}

O conceito de Modelo Mental disseminou-se a partir da publicação, em 1983, de dois livros sobre o tema, dentre os quais, Mental Models de Johnson-Laird. Nele, o autor busca explicar o raciocínio dedutivo e a compreensão do texto escrito. Propõe que os "modelos mentais são análogos estruturais de estados de coisas do mundo", sendo, portanto, representações internas de informações que correpondem analogamente ao que está sendo representado (JONHSON-LAIRD, 1983 apud SOUSA; MOREIRA, 2000). Portanto, um modelo mental é uma representação analógica, que Moreira (1996) afirma poder se dar em nível de analogia parcial ou analogia total.

Um modelo mental também pode ser parcialmente proposicional, apesar de que as proposições são interpretações em relação a modelos mentais. Assim, uma proposição é considerada verdadeira ou falsa em relação a um modelo mental de um estado de coisas do mundo, enquanto as imagens correspondem às vistas do modelo.

Sousa e Moreira (2000, p. 226) esclarecem que:

Para Jonhson-Laird os modelos mentais e as imagens são representações de alto nível, essenciais para o entendimento da cognição humana. Mesmo que em seu nível básico a mente humana possa computar as imagens e os modelos mentais em algum código proposicional, o uso de modelos mentais e imagens (perspectivas dos modelos) libera a cognição da obrigação de operar proposicionalmente nesse código. Assim como o computador opera com um código binário, mas os programadores trabalham com linguagem de alto nível, a mente humana, em última instância, operaria com algum código próprio, mas seu funcionamento poderia ser descrito em termos de modelos mentais, imagens e proposições sem ter acesso (e, de fato, não se tem, pois é não-consciente) a esse código.

Para Jonhson-Laird os modelos mentais e as imagens são representações de alto nível, essenciais para o entendimento da cognição humana. Mesmo que em seu nível básico a mente humana possa computar as imagens e os modelos mentais 
em algum código proposicional, o uso de modelos mentais e imagens (perspectivas dos modelos) libera a cognição da obrigação de operar proposicionalmente nesse código. Assim como o computador opera com um código binário, mas os programadores trabalham com linguagem de alto nível, a mente humana, em última instância, operaria com algum código próprio, mas seu funcionamento poderia ser descrito em termos de modelos mentais, imagens e proposições sem ter acesso (e, de fato, não se tem, pois é não-consciente) a esse código (SOUSA; MOREIRA, 2000, p. 226).

Portanto, para Johnson-Laird, a compreensão implica a construção de modelos mentais. Assim, quando compreendemos algo, sendo capazes de fazer uma descrição desse algo, de dizer como funciona, e de fazer inferências, é porque temos um modelo mental desse algo (SOUSA; MOREIRA, 2000). Isso implica dizer que os sujeitos usam modelos mentais para raciocinar e não uma lógica mental. A lógica não surge na elaboração do modelo mental, mas na testagem da aplicação do modelo, quando os sujeitos tiram conclusões.

Apesar da crescente discussão sobre Modelos Mentais, ainda não há consenso sobre uma definição para este constructo na literatura. No entanto, o significado que parece mais adequado ao trabalho que aqui é proposto, integra uma vertente que parte da proposta teórica de Johnson-Laird (1983 apud SOUSA; MOREIRA, 2000) que, ao ir além da conceituação, aborda a tipologia de modelos mentais conceituais.

Os modelos mentais conceituais são aqueles que representam as coisas abstratas. Nesse sentido, os modelos mentais são construídos pelos sujeitos a partir de eventos e estados do mundo exterior, empregando processos mentais tácitos.

Em síntese, é importante compreender que os modelos mentais são ativos e, consequentemente, determinam não apenas a forma como os sujeitos entendem o mundo, mas também suas formas de agir. E é a forma como os modelos mentais moldam a percepção dos sujeitos que tem grande importância no mundo das organizações. 


\subsection{Modelos mentais e estratégia da organização pública}

Como observou-se, o conhecimento de mundo dos sujeitos depende de sua capacidade de construir modelos mentais. Assim, como os modelos mentais são mediadores das relações entre o sujeito e o mundo que o cerca, a forma como concebe o mundo apresenta-se como fator de restrição para as suas construções, que podem influenciar na capacidade dos sujeitos de resolver situações-problemas cotidianas. Silva (2001 apud TÔRRES, 2005, p. 66), acrescenta que eles "modelam nossa percepção da realidade e, portanto, nossas decisões e ações para todos os aspectos de nossa experiência humana no universo".

Senge (2008, p. 213) observa, no entanto, que "os modelos mentais mais cruciais em qualquer organização são os compartilhados pelos principais responsáveis pelo processo decisório". Isso implica dizer que o sujeito, no processo de gestão, precisa ter um modelo mental em contínua interação com o ambiente, para que alcance novas habilidades, potencialidades e capacidades de atender às necessidades da organização.

De acordo com Silva (2001 apud TÔRRES, 2005), muitas excelentes novas ideias não são implementadas por serem conflitantes com modelos mentais, caracterizando que vivemos em uma crise de percepção. Silva acredita que essa crise é decorrente do fato de que as ações implementadas são orientadas pelos conceitos de uma visão de mundo obsoleta, portanto, inadequada para lidar com o mundo que é cada vez mais complexo. Segundo Silva, (2001 apud TÔRRES, 2005, p. 66), "deixamos, não só de reconhecer como diferentes problemas estão inter-relacionados, mas também nos recusamos a reconhecer como nossas soluções afetam as outras pessoas e até mesmo as gerações futuras". Isso implica dizer que muitos gestores fixam suas decisões a partir de visões de mundo estagnadas que já não atendem a realidade de constantes mudanças.

Mintzberg, Ahlstrand e Lampel (2000, p. 119), afirmam que "não existe falta de evidências a respeito de organizações que ficaram presas a maneiras fixas de fazer as coisas, baseadas em maneiras fixas de vê-las", dentre as quais, citamos as organizações do setor público. 
No Brasil, as organizações públicas permaneceram engessadas durante as fases da Administração Pública Patrimonialista e Burocrática.

A Administração Pública Patrimonialista sucedeu o regime imperialista e herdou a tendência de gestão que prioriza o servidor público e a garantia do patrimônio do Estado, em detrimento da sociedade, o que contribuiu para a prática da corrupção e do nepotismo. Aproximadamente trinta anos após, surgiu a Administração Pública Burocrática, com a principal finalidade de fazer frente às mazelas da Administração Patrimonialista combatendo a corrupção e o nepotismo por meio do modelo burocrático de gestão. A partir de então, a administração pública brasileira sofreu grande evolução, no entanto, o modelo burocrático priorizou excessivamente o Estado, deixando o cidadão em segundo plano, não concedendo à sociedade a importância devida na consecução das políticas públicas (JUND, 2006). Isso implica no fato de, ainda que o modelo de gestão tenha sofrido mudanças, manteve-se a base conceitual dos modelos mentais estabelecidos pelos gestores, uma vez que a visão burocrática permeou todas as ações gerenciais.

No entanto, no decorrer da segunda metade do século XX, emerge a Administração Pública Gerencial, impulsionada pela globalização da economia e pela explosão tecnológica mundial, que instigou as organizações a pensarem estrategicamente, visando garantir a sobrevivência. Segundo Jund (2006), esse modelo aperfeiçoou o papel do estado na medida em que empreendeu a necessidade dos cidadãos serem priorizados nas organizações, permitindo sua participação nas decisões estratégicas, a fim de atender as necessidades sociais de forma mais eficiente possível. Contudo, como estratégia, serve-se da descentralização e do incentivo à criatividade e à inovação, utilizando o contrato de gestão como instrumento de controle dos gestores públicos.

Dessa forma, surgem dois grandes desafios diante dos gestores públicos: $1^{\circ}$ ) importar para a administração pública os meios utilizados nas organizações privadas, preservando os aspectos de legalidade impostos, cujo princípio se conserva na lógica ditada pelo direito público, que impõe ao administrador praticar apenas o previsto em lei, tirando dela os melhores proveitos em favor da melhoria das organizações públicas, com a adoção de modelos de gestão mais modernos, a 
exemplo do planejamento estratégico; $2^{\circ}$ ) considerar os modelos mentais como fatores imprescindíveis para a compreensão do processo de gestão, em decorrência de que muitas modificações administrativas são impedidas de serem transformadas em políticas operacionais por serem conflitantes com modelos mentais tácitos, incluindo ideias arraigadas e paradigmas que interferem sobre as atitudes dos sujeitos, muitas vezes sem que se tenha consciência disso, mas afetando pontualmente a realização da estratégia da organização. Logo, implica destacar a afirmativa de Chaves (2007), ao dizer que o desafio de implementar políticas públicas mais eficientes em prol da sociedade permanece e se avoluma à medida que os desafios gerenciais se concentram nos gestores, exigindo deles maior capacidade para fazer frente à complexidade do contexto atual e da própria administração.

\section{Pensamento estratégico na prática gerencial}

O conceito de gestão estratégica é muito mais amplo que o conceito de planejamento estratégico, havendo, segundo Oliveira (2006), certa dificuldade quanto à conceituação da função do planejamento de estabelecer sua real amplitude e abrangência.

Bertaglia (2003), diz que o planejamento engloba desde a participação efetiva da alta administração, do envolvimento e comprometimento dos servidores, além das avaliações dos cenários, diagnósticos, da estruturação do processo de planejar e formular um propósito compartilhado para a organização, a escolha de estratégias, a fixação de metas e desafios, até a atribuição de responsabilidades para o detalhamento dos planos e projetos e para conduzir e acompanhar as etapas de sua implantação.

Enquanto isso, Mintzberg e Quinn (2001) reafirmam que há uma grande diferença entre gestão estratégica e o planejamento estratégico tradicional, ressaltando que tal distinção é decorrente da observação, da experiência e da constatação de muitos analistas, executivos e consultores, de que planos perfeitos, elaborados pelas empresas mais famosas do mundo ou pelos consultores mais experientes, acabam sendo engavetados, sem nunca se tornarem realidade, caindo no esquecimento, quando não no descrédito. 
Mintzberg, Ahlstrand e Lampel (2000) propõem dez escolas de pensamento sobre formulação de estratégia, com pontos de vista distintos, e a maioria dos quais se reflete na prática gerencial: a Escola do Design trata da formulação de estratégia como um processo de desenho informal, essencialmente de concepção; a Escola do Planejamento aborda a formulação de estratégia como um processo de planejamento formal, separado e sistemático; A Escola do Posicionamento enfoca a formulação de estratégia como um processo analítico, focalizando a seleção de posições estratégicas no mercado; a Escola Empreendedora retrata a formulação de estratégia como um processo visionário, associando a estratégia com espírito empreendedor e descrevendo o processo em termos da criação da visão pelo "grande líder"; a Escola Cognitiva ensina a formulação de estratégia como um processo mental, que busca usar as mensagens da psicologia cognitiva para entrar na mente do estrategista; a Escola de Aprendizado mostra a formulação de estratégia como um processo emergente, ou seja, a estratégia deve emergir na medida em que a organização se adapta ou "aprende"; a Escola do Poder possibilita a formulação de estratégia como um processo de negociação, seja por grupos conflitantes dentro da organização ou pelas próprias organizações, enquanto confrontam seus ambientes externos; a Escola Cultural prevê a formulação de estratégia como um processo coletivo e cooperativo, considerando a estratégia como sendo enraizada na cultura da organização; a Escola Ambiental mostra a formulação de estratégia como um processo reativo, no qual a iniciativa não está dentro da organização, mas em seu contexto externo; e finalmente, a Escola de Configuração se reporta à formulação de estratégia como um processo de transformação, incorporando grande parte da enorme literatura e da prática prescritiva sobre mudanças estratégicas.

Cada escola de pensamento focaliza uma perspectiva, um aspecto importante do processo de formulação de estratégia. Assim, para corroborar a noção de Estratégia como elemento fundamental no processo de construção do próprio Planejamento Estratégico; Mintzberg, Ahlstrand e Lampel (2000) afirmam que, embora o todo seja mais que a soma das partes (escolas de pensamento), é necessário entender as partes para apreciar o todo. Isso é o que as escolas sugerem: conhecer as peculiaridades e os mais surpreendentes aspectos presentes na formulação de estratégia, presentes em cada uma delas, o que pontua a importância de todas as 
escolas de pensamento para a compreensão do processo de estratégia, por meio da combinação dos vários aspectos das diferentes escolas.

No entanto, combinar os vários aspectos das diferentes escolas de pensamento no processo de estratégia requer dos gestores trazer à superfície os modelos mentais, explorar e falar sobre eles com o mínimo de espírito defensivo, desacelerando os processos de pensamento para ficar mais consciente de como os modelos mentais são formados e mantendo conversações abertas em que possam compartilhar visões e desenvolver conhecimentos acerca dos seus pressupostos, conforme sugere Senge (2008).

Portanto, é necessário não somente que exista um planejamento estratégico, mas, sobretudo, um pensamento estratégico que envolva todos os participantes da organização, a fim de proporcionar o empenho de todos os elementos na constituição da estratégia com o firme propósito de torná-la uma realidade.

\section{Estratégica e aprendizagem em tempos de incertezas}

Na existência do pensamento estratégico, o planejamento estratégico apresenta-se, portanto, como uma ferramenta que pode auxiliar na tomada de decisão com uma margem menor de erros no contexto organizacional. A partir dele são analisados os cenários, formuladas estratégias, propostos os objetivos, as metas e as ações das organizações, sejam nos processos produtivos ou na prestação de serviços. Barbosa e Brondani (2004, p. 108) observam que "existem três tipos de organizações: as que fazem acontecer, as que apenas observam acontecer e as que surpreendentemente se espantam com o que aconteceu”. Assim, por meio do planejamento, as organizações podem se projetar e criar alternativas de adaptação às mudanças ou permanecer apáticas diante de forças internas e externas que afetam o seu cotidiano. Mintzberg, Ahlstrand e Lampel (2000) entendem a estratégia como aprendizado, visão e política; e considerando a velocidade com que tudo muda, observam que é incoerente fazer afirmações sobre o futuro. A administração estratégica seria uma comunidade de exploradores de princípios, de base, de olhar questionador. 
Numa perspectiva histórica, Mintzberg, Ahlstrand e Lampel (2000) dizem que a influência de Frederick Taylor é muito forte nas organizações e no planejamento estratégico, acrescentando que um dos maiores erros dos gestores é levar demasiadamente a sério um ponto de vista, é verem a formação estratégica como processo único. A Escola da Aprendizagem, em seu olhar, preocupa-se com os "pormenores". É definida como descritiva, o crescimento é mais natural, e os gestores podem realizar enxertos para ver o que acontece. Dessa forma, entende que a formulação da estratégia é um processo emergente e, caso ocorra fracasso na implementação, será devido a um fracasso na formulação. Logo, qualquer pessoa que seja bem informada é importante no processo estratégico em uma organização.

Para Mintzberg, Ahlstrand e Lampel (2000), as premissas da escola da aprendizagem formam um conjunto de ideias não planejadas e com novas direções para o aprendizado estratégico, podendo ser compreendidas na visão das organizações que aprendem na teoria do caos, na teoria revolucionária e na abordagem da capacidade dinâmica.

A escola da aprendizagem desenvolveu dois tipos de conceitos: a estratégia emergente e a compreensão retrospectiva. Enquanto a estratégia deliberada realiza plenamente as intenções, prioriza o controle e quase exclui o aprendizado, a estratégia emergente "abre a porta para o aprendizado estratégico, porque reconhece a capacidade da organização para experimentar” (MINTZBERG; AHLSTRAND; LAMPEL, 2000, p. 143). A estratégia emergente vai além de um líder individual ou de uma pequena equipe que gerencia, pode também ser desenvolvida em coletividade. À medida que as pessoas interagem, geram conflitos e aprendem umas com as outras desenvolvendo o consenso.

Quanto à visão de estratégia deliberada, muitas questões estratégicas ficam sob o controle direto de profissionais individuais ou de dirigentes centrais. Nas organizações que aprendem, a participação das pessoas acontece em um processo de interação complexa, obedecendo a processos simples.

$\mathrm{Na}$ escola da aprendizagem, mesmo em casos extremos, a realidade do comportamento estratégico deve combinar aprendizagem emergente e controle. 
A aprendizagem emergente é associada ao aprendizado que combina a reflexão do que os agentes fizeram com os resultados alcançados, "trata-se de um rompimento com décadas de tradição em administração estratégica, a qual tem insistido que o pensamento deve terminar antes que a ação se inicie - que a formulação deve ser seguida com a implementação" (MINTZBERG; AHLSTRAND; LAMPEL, 2000, p. 149). Sob essa concepção, não se pode esperar uma análise primeiro e integração depois.

O comportamento das pessoas em qualquer nível da organização deve mudar de modo a derrubar as defesas que bloqueiam o aprendizado. Nonaka e Takeuchi (1995 apud MINTZBERG; AHLSTRAND; LAMPEL, 2000, p. 158), afirmam que "a essência da estratégia está no desenvolvimento da capacidade organizacional para adquirir, criar, acumular e explorar o conhecimento". Somente os indivíduos podem criar conhecimento, enquanto as organizações são facilitadoras desse processo e devem apoiar e estimular o desenvolvimento do aprendizado individual em nível de grupo.

Prahalad e Hamel enfatizam em seus estudos a estratégia como dependente do aprendizado e, por conseguinte, das capacidades. Essa abordagem tende a considerar a administração estratégica como um processo de aprendizado coletivo, aponta a competência central como consequência do aprendizado coletivo, que pode ser identificado de três modos: primeiro, provê acesso a uma ampla variedade de mercados; segundo, contribui significativamente para o beneficio do produto final oferecido ao cliente e; terceiro, deve ser difícil de ser imitada pelos concorrentes (MINTZBERG; AHLSTRAND; LAMPEL, 2000).

$\mathrm{Na}$ abordagem tradicional, o controle, a ordem e a previsibilidade foram institucionalizadas na rotina das organizações. A desordem, o caos é visto como prejudicial. Nonaka (1988 apud MINTZBERG; AHLSTRAND; LAMPEL, 2000, p. 166) e Stacey (1992 apud MINTZBERG; AHLSTRAND; LAMPEL, 2000, p. 166), afirmam que a "desordem e caos são propriedades intrínsecas, e não estranhas às organizações”. Esses autores propõem que os gestores, deliberadamente, deveriam injetar perturbações nas operações com o intuito de que essas inconsistências pudessem gerar novos conhecimentos. A sugestão da teoria do caos é de que quase 
tudo pode acontecer e que pequenas perturbações podem surtir grandes efeitos necessários, proporcionando aos gestores flexibilidade para que possam melhor se adaptar às novas maneiras de ver as coisas. Mintzberg, Ahlstrand e Lampel (2000, p. 166) reforçam que as lições da teoria do caos para a administração estratégica estão no fato de que "as coisas são tão caóticas, tão desordenadas, que aqueles que são flexíveis e se movimentam depressa podem aproveitar oportunidades por toda parte". Quem sente dificuldade e sofre por não saber lidar com a desordem e aproveitar oportunidades são os burocratas e os planejadores.

Dessa forma, as lições da teoria do caos para a administração estratégica assemelham-se às técnicas de modelos mentais, que sugerem a prática do aprendizado contínuo, por meio da flexibilidade do estrategista e de sua atenção às visões de curto e longo prazo, na perspectiva de que as mudanças ocorrem rapidamente e de forma imprevisível.

\section{Planejamento estratégico como gestão da mudança}

As organizações, segundo Bar (2000, p. 70) "são redes de agentes, pessoas que interagem umas com as outras, de acordo com um conjunto de regras comportamentais, um esquema de ordem social que se assemelha aos sistemas de organismos vivos, imprevisíveis, portanto". Com isso, sua conduta no futuro não pode ser prevista pelo comportamento passado, uma vez que "as diferenças das condições iniciais são quase sempre imperceptíveis e levam a uma sucessão de reações do sistema, causadoras de um comportamento completamente diferente" (ROSENHEAD, 1998 apud BAR, 2000, p. 70).

Como o futuro é imprevisível, o grande desafio que se apresenta como trabalho gerencial, de acordo com Bar (2000, p. 70) "é tomar decisões sobre os caminhos de suas organizações". Isso implica dizer que o planejamento estratégico não é gestão para mudança, mas sim, gestão da mudança. Dessa forma, o planejamento estratégico é a gestão da mudança da posição atual da organização para a posição desejável. A estratégia é um conceito com propósito de estabilidade, não de mudança. As organizações, conforme Mintzberg, Ahlstrand e Lampel (2000) seguem 
estratégias para fins de consistência, mas algumas vezes, elas também precisam de mudanças estratégicas - precisam descartar suas direções estabelecidas em resposta a um ambiente mudado.

O planejamento estratégico pressupõe a necessidade de um processo decisório que ocorrerá antes, durante e depois de sua elaboração e implementação. Ainda, inerente ao processo decisório, é preciso considerar a existência de condicionantes organizacionais que afetam sua operacionalização, com a implicação de restrições de ordem prática, corroborando com Oliveira (2006). Dentre os fatores de impacto na operacionalização do planejamento estratégico estão: o poder político, a aprendizagem, a comunicação, o trabalho em equipe e a liderança.

O poder político implica na capacidade das pessoas em defender seus interesses frente às formas de poder presentes na organização. Assim, na tomada de decisão, é preciso observar o que pode e deve ser feito, e não o que seria certo fazer, sem, contudo, interferir nas relações de poder existentes na organização, a fim de fazer as pessoas colaborarem e aceitarem as mudanças, e minimizarem o risco de tornar o planejamento estratégico estéril.

Quanto à aprendizagem, por estar orientada para a adaptação da organização ao contexto ambiental, o planejamento estratégico constitui uma tentativa constante de aprender a ajustar-se a um ambiente complexo, competitivo e suscetível a mudanças; porém a efetivação das propostas dependerá em grande escala da flexibilidade da organização às mudanças.

A comunicação, como um fator de impacto no planejamento estratégico, nem sempre é bem utilizada na organização. Deve possuir um caráter bilateral na relação psicossocial. Falar, ler, ouvir, raciocinar e escrever são habilidades necessárias para que a comunicação aconteça. As habilidades compreendem: conhecimento (qualidade/quantidade); sistema sociocultural (posição que o indivíduo ocupa no grupo, seus valores e crenças) e atitudes (ideias pré-concebidas que fazem parte da história do indivíduo). Nem sempre as atitudes demonstram o comportamento das pessoas. A comunicação só é produtiva quando consegue gerar reciprocidade na relação dos sistemas. 
O trabalho em equipe destaca-se como imprescindível na operacionalização das ações do plano estratégico, em virtude de que todas as decisões importantes são tomadas em equipe, seja diretamente ou por meio da necessidade de equipes para traduzir as decisões individuais em ação.

Outro fator impactante na operacionalização do planejamento é a forma como a liderança se dá na organização. As oportunidades desafiadoras, as incertezas em todo o mundo, a busca por respostas, a globalização, entre outras, evidencia a figura do líder na atualidade. Para Kauzes e Posner (2003), o grande desafio é liderar em época de caos e incertezas, considerando a existência de padrões e práticas de liderança que podem ser aprendidas. Ainda, segundo Kauzes e Posner (2003, p. 32-33), "a liderança não é personalidade, liderança é prática" e as cinco regras básicas de liderança são: 1) apontar o caminho; 2) inspirar uma visão compartilhada; 3) desafiar o estabelecido; 4) permitir que os outros ajam; e 5) encorajar o coração. Essas regras básicas não são suficientes para ser um líder, porém, é uma preparação para que seja criado um ambiente de aceitação e credibilidade entre líder e liderado.

Ocorre que o poder político, a aprendizagem, a comunicação, o trabalho em equipe e a liderança, como fatores de impacto na operacionalização do planejamento estratégico, estão fundamentados em outro elemento limitador da operacionalização do plano: os modelos mentais das pessoas.

Mintzberg, Ahlstrand e Lampel (2000) alertam para o fato de que, embora as organizações busquem estabilidade por meio das estratégias, precisam ter flexibilidade em respota a um ambiente de mudança, e considerar a existência de condicionantes que afetam a operacionalização de bons planos e projetos gerenciais. Isso requer considerar as possíveis implicações dos modelos mentais dos gestores, não somente na elaboração e implementação, mas, sobretudo, na consecução das estratégias da organização. 


\section{Aspectos do planejamento estratégico do Poder Judiciário de Rondônia}

O Plano Estratégico do Poder Judiciário de Rondônia (PE-PJRO) foi elaborado em abril de 2007 e revisado em 2009, por meio de oficinas de trabalho (workshops) utilizando uma metodologia baseada no equilíbrio organizacional, que monitora o desempenho da organização em pontos críticos para seu sucesso, o Balanced Scorecard.

O cenário observado na consecução do PE-PJRO buscou conhecer as características atuais do ambiente externo, tendências futuras, possibilidades e perspectivas como: aumento dos conflitos sociais; aumento populacional; ampliação da credibilidade na Justiça; inovação tecnológica; otimização dos gastos públicos; população mais informada e exigente dos seus direitos; preservação do meio ambiente; qualidade de vida; responsabilidade social; e terceirização dos serviços básicos.

O ambiente interno da organização foi analisado visando identificar os principais pontos fortes e fracos. A partir do conhecimento de suas forças e fraquezas, a organização adquire indicações da existência de problemas que devem ser investigados, encaminhados e tratados convenientemente no plano estratégico da instituição. O diagnóstico dessas consequências permitirá, em tese, que sejam tratadas as causas e adotadas medidas de mitigação e eliminação dos fatores supervenientes.

A missão do PJRO foi definida como: "Oferecer à sociedade efetivo acesso à Justiça”.

Quanto à visão da organização, está definida no seguinte prospecto: "Ser uma instituição acessível, que promova justiça com celeridade, qualidade e transparência”.

Para o balizamento de seu processo decisório, o PJRO também reconhece como atributos de valor para a sociedade: acessibilidade, ética, imparcialidade, modernidade, probidade, equidade e responsabilidade social e ambiental. 
Os objetivos estratégicos do PJRO estão definidos sob quatro perspectivas, a saber: (1) Sociedade, com o objetivo principal de tornar acessíveis os serviços do PJRO dentro da expectativa dos usuários e promover a efetividade no cumprimento das decisões judiciais; (2) Processo, com o objetivo de melhorar a efetividade de sua gestão e controle por meio da otimização dos processos de trabalho; 3) Recursos, que buscam adequar a estrutura material e lógica à demanda e, assegurar recursos orçamentários para a execução da estratégia; e (4) Pessoas, com o objetivo de valorizar o conhecimento e a competência das pessoas, para a transformação dos modelos vigentes de gestão.

\section{Resultado e discussão dos dados}

Conforme observa Creswell (2007, p. 194), a análise e interpretação dos dados "é um processo constante envolvendo refletir continuamente sobre os dados, fazer perguntas analíticas e redigir memorandos durante todo o estudo. Isso não é nitidamente separado de outras atividades no processo, como coleta de dados ou formulações de questões de pesquisa”. Dessa forma, os dados são apresentados e analisados simultaneamente, com o objetivo de aprofundar-se cada vez mais no seu entendimento para fazer uma interpretação do significado mais amplo. Os principais resultados coletados na pesquisa com os dez gestores são os que seguem.

\subsection{Comunicação existente na organização}

A comunicação e o relacionamento pessoal dos profissionais envolvidos nas atividades de planejamento da organização, conforme 70\% dos gestores (figura 1), além de facilitar as atividades de planejamento, facilitam completamente a integração de áreas, processos, fornecedores e clientes, demonstrando que a comunicação na organização é produtiva, uma vez que consegue gerar reciprocidade na relação dos sistemas. 
Figura 1: Comunicação e Relacionamento Pessoal

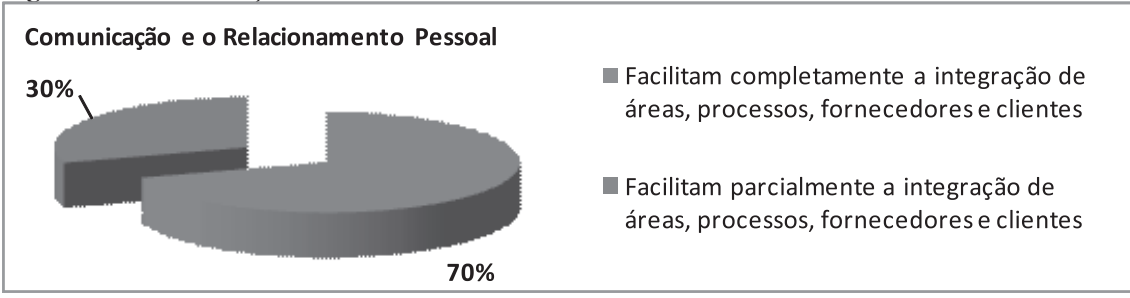

Fonte: Dados da Pesquisa

\subsection{Atividades pertinentes ao planejamento estratégico da organização}

A troca de experiência e de aprendizado entre os profissionais envolvidos nas atividades de planejamento é totalmente promovida pela organização (figura 2) possibilitando, portanto, o aprendizado, o que é favorável para a organização, por ser imprescindível na operacionalização das ações do plano estratégico, considerando que todas as decisões importantes são tomadas em equipe, seja diretamente ou por meio da necessidade de equipes para traduzir as decisões individuais em ação.

Figura 2: Troca de Experiência

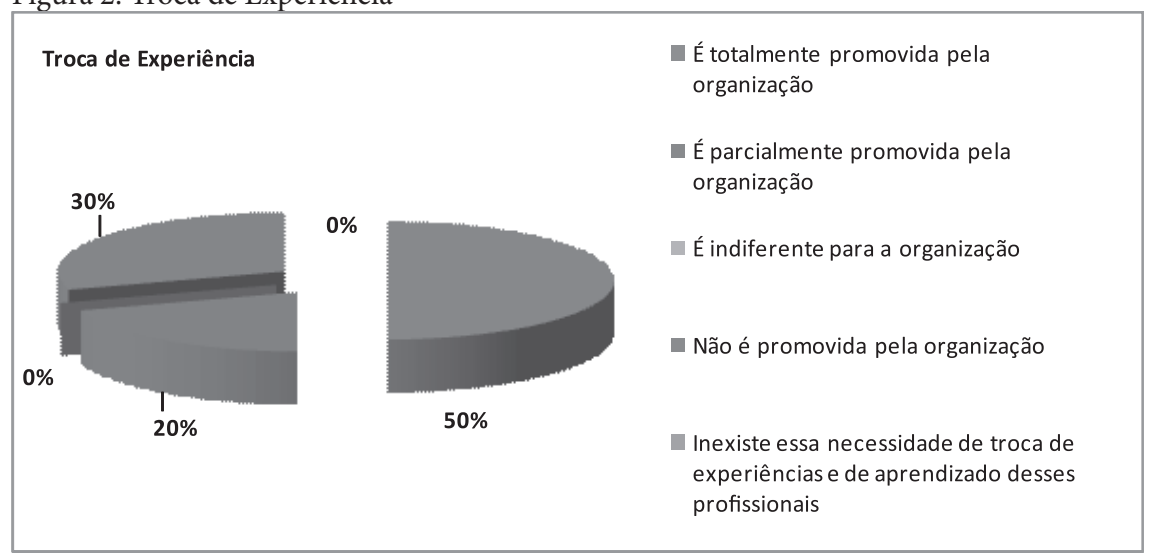

Fonte: Dados da Pesquisa 
Quanto aos eventuais erros dos profissionais envolvidos nas atividades de planejamento (figura 3), 40\% dos gestores apontaram que são totalmente interpretados como parte do processo de desenvolvimento e aprendizado, enquanto $30 \%$ indicaram que são parcialmente interpretados como parte do processo de desenvolvimento e aprendizado, índices que sinalizam para o aprendizado estratégico, porque reconhece a capacidade da organização para experimentar, conforme Mintzberg, Ahlstrand e Lampel (2000).

Figura 3: Eventuais Erros

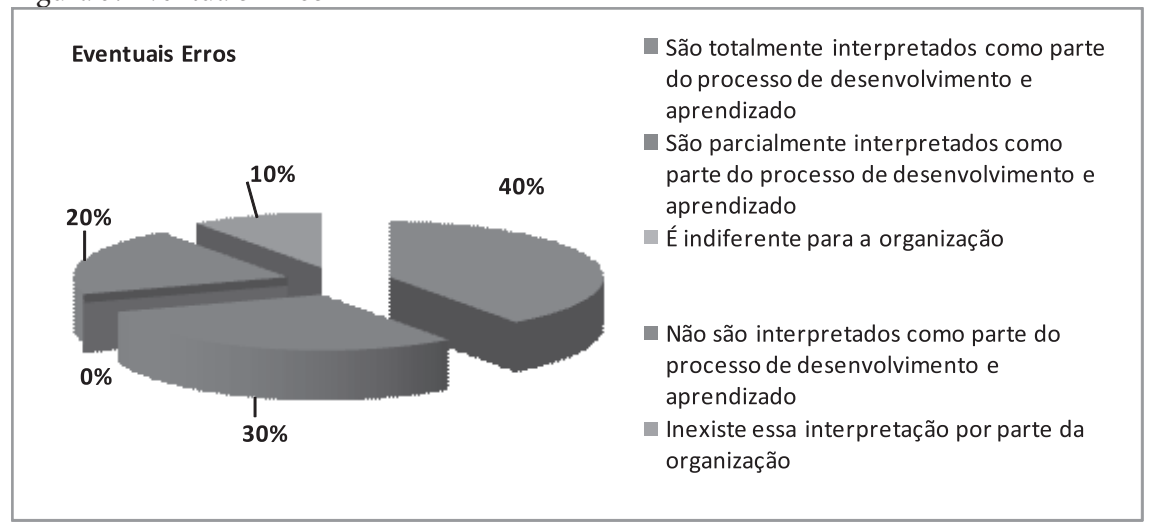

Fonte: Dados da Pesquisa

Com relação ao envolvimento dos gestores nas atividades de planejamento da organização, 70\% dos gestores, conforme apresentados na figura 4, expressam parcial vontade e motivação para realizar essas atividades, o que por ser fator de impacto no PE e esta afirmação não permitir identificar suas causas, indica a necessidade de realização de outros estudos mais criteriosos que permitam entender melhor o problema. 
Figura 4: Envolvimento

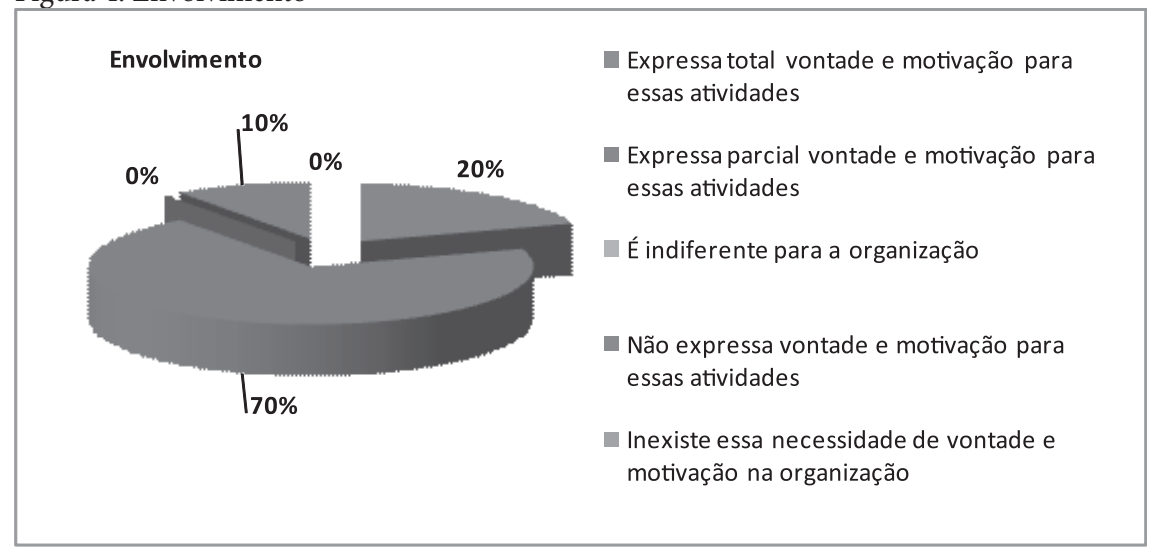

Fonte: Dados da Pesquisa

\subsection{Quanto ao alinhamento - questão aberta}

Quanto ao percentual de alinhamento entre o planejamento estratégico e a execução prática dele na organização, sob o ponto de vista dos pesquisados, conforme figura 5; ficou demonstrado que apenas 30\% dos gestores percebem algum alinhamento, enquanto $50 \%$ não quiseram opinar, e $10 \%$ responderam não poder afirmar qualquer percentual de alinhamento, remetendo-nos à reflexão de Mintzberg de que, não havendo estratégia emergente o planejamento estratégico quase sempre não sai do papel. É válido, nesse momento, considerar o resultado da pesquisa quanto ao envolvimento dos gestores nas atividades de planejamento, pois é necessário não somente que exista um planejamento estratégico, mas, sobretudo, um pensamento estratégico que envolva todos os participantes da organização, a fim de proporcionar o empenho de todos os elementos na constituição da estratégia com o firme propósito de torná-la uma realidade. 
Figura 5: Questão Aberta

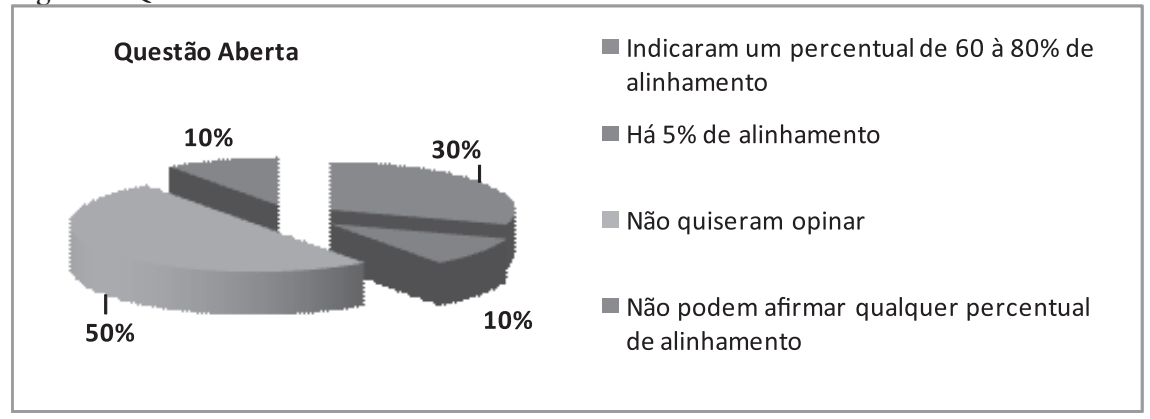

Fonte: Dados da Pesquisa

\subsection{Quanto aos modelos de gestão adotados pela organização}

Os modelos de gestão adotados pela organização, no passado, não foram alinhados às estratégias da organização para $40 \%$ dos gestores dos projetos estratégicos, enquanto $50 \%$ afirmaram que foram parcialmente alinhados às estratégias (figura 6), o que se apresenta como fator de restrição para o PE/TJRO, uma vez que a visão de mundo estabelecida a partir de experiências vividas, arraiga modelos mentais que podem influenciar fortemente na capacidade das pessoas se posionarem diante de situações-problemas, o que nos remete à reflexão de Silva (2001 apud TÔRRES, 2005), que muitas excelentes novas ideias não são implementadas por serem conflitantes com modelos mentais.

Figura 6: Modelos de Gestão

\begin{tabular}{|l|l|} 
Modelo de Gestão & $\begin{array}{l}\text { Foi totalmente alinhado à estratégia da } \\
\text { organização }\end{array}$ \\
Foi parcialmente alinhado à estratégia \\
da organização \\
É indiferente para a organização \\
Não foi alinhado à estratégia da \\
organização \\
Inexistiu a necessidade de alinhamento \\
à estratégia da organização
\end{tabular}

Fonte: Dados da Pesquisa 
Figura 7: Planejamento Estratégico

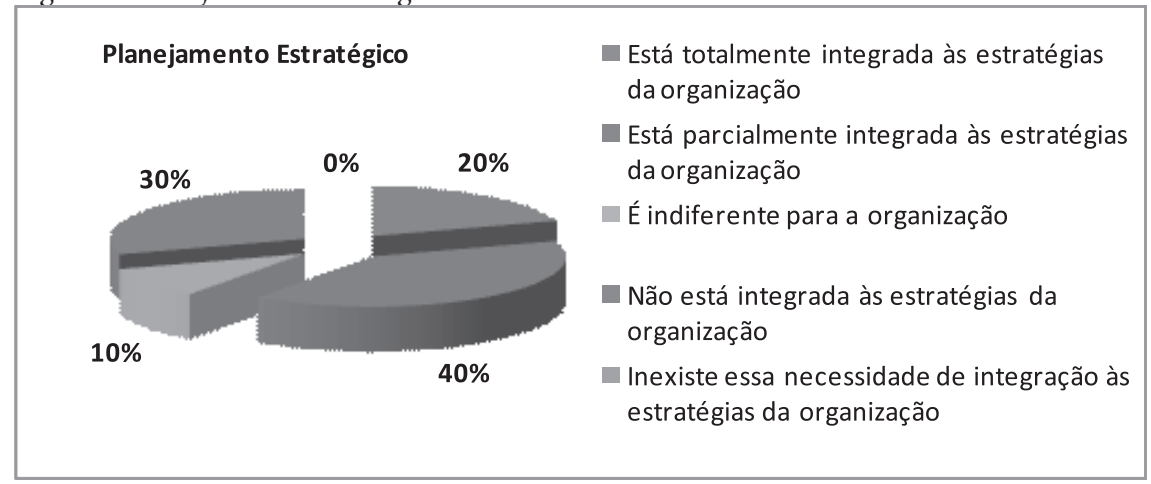

Fonte: Dados da Pesquisa

Quanto à adoção do planejamento estratégico pela organização (figura 7), apesar de $40 \%$ dos gestores apontarem que está parcialmente integrado às estratégias da organização, 30\% apontam que ele não está integrado às estratégias, bem como $10 \%$ acreditam que o alinhamento seja indiferente para a organização, o que remete à observação de Mintzberg, Ahlstrand e Lampel (2000, p. 119), que "não existe falta de evidências a respeito de organizações que ficaram presas a maneiras fixas de fazer as coisas, baseadas em maneiras fixas de vê-las", comprometendo, portanto, a consecução das suas estratégias definidas e qualidade dos serviços prestados pelo Poder Judiciário de Rondônia.

\section{Considerações finais}

O Planejamento Estratégico do Poder Judiciário de Rondônia - PE/PJRO obedece a critérios de um planejamento estratégico tradicional, despontando para novas formas de ver o planejamento, ao considerar, dentre outros princípios, o comprometimento, o trabalho em equipe, a valorização das competências das pessoas e a necessidade de aprendizado pela organização. No entanto, como todo planejamento estratégico pressupõe a necessidade de um processo decisório antes, durante e depois de sua elaboração e implementação, considerar a exis- 
tência de condicionantes organizacionais que afetam sua operacionalização, com a implicação de restrições de ordem prática, conforme Oliveira (2006) torna-se imprescindível.

Dessa forma, este estudo verificou que o comprometimento dos gestores sinaliza perspectivas desfavoráveis à consecução das estratégias estabelecidas no Planejamento Estratégico do PJRO, ao observar que muitos gestores fixam suas decisões a partir de visões de mundo estagnadas, mesmo que o modelo de gestão tenha sofrido mudanças e a organização apresente disposição para a aprendizagem, mantendo-se a base conceitual dos modelos mentais estabelecidos a partir de experiências mal sucedidas. Implica dizer que os modelos mentais não foram criteriosamente considerados no processo decisório ocorrido antes e durante a elaboração e implementação do Planejamento Estratégico do TJRO, como condicionante que afetaria sua operacionalização. Diante disso, é imprescindível considerar a necessidade de trazer à superfície os modelos mentais dos gestores, explorar e falar sobre eles com o mínimo de espírito defensivo, desacelerando os processos de pensamento para que possam tornar-se mais conscientes de como estão sendo formados seus modelos mentais sobre as propostas apresentadas pela organização, afim de que haja comprometimento na consecução das estratégias definidas, conforme sugere Senge (2008).

Outro fator de impacto consiste no fato de que os modelos mentais compartilhados pelos principais responsáveis pelo processo decisório, também gestores das unidades responsáveis pela coordenação da operacionalização das estratégias no TJRO, ainda não estão em contínua interação com o ambiente, o que pode implicar fortemente em restrições para que sejam alcançadas novas habilidades, potencialidades e capacidades para atender às necessidades da organização em seu propósito de melhorar a prestação dos serviços jurisdicionais. Consequentemente, não havendo disposição dos gestores para experimentar, a capacidade da organização para aprender fica limitada ao atendimento das estratégias deliberadas, dissociando o plano estratégico do pensamento estratégico, atitude inadequada em um mundo cada vez mais complexo. 


\section{Mental Models as a Conditioning of Strategic Thinking: Study on the Judiciary of the State of Rondônia}

\section{Abstract}

This study aimed to verify how mental models can influence the strategic thinking in achieving of the strategies set out in the Strategic Plan of the judicial branch of the government of State of Rondônia/Brazil, called Poder Judiciário do Estado de Rondônia - PJRO, which seeks to improve the quality of services provided by the Judiciary. The methodology used was descriptive and exploratory study and the analysis considered the qualitative approach. The approach of the study on mental models has been made in view of Johnson-Laird, that proposes the mental models as mediators of relations between the subject and the world that surrounds, while the approach on strategic planning was done from the perspective of Mintzberg with focus on School of Learning, seeking to understand the strategic planning towards an alive organization where the individuals must think strategically. This study found that persists at PJRO the decision-making based in the perspective of mental models established in personal experiences gained at work, unfavorable to the emergence strategic thinking.

Keywords: Mental models. Strategic thinking. Judiciary.

\section{Referências}

BAR, Fernando Luis. Planejamento estratégico em tempos de caos e complexidade. Alcance (Administração), Itajaí, ano 7, n. 1, p. 69-73, jun. 2000.

BARBOSA, Emerson Rodrigues; BRONDANI, Gilberto. Planejamento estratégico organizacional. Revista Eletrônica de Contabilidade, Santa Maria, v. 1, n. 2. dez. 2004/fev. 2005.

BERTAGLIA, Paulo Roberto. Logística e gerenciamento da cadeia de abastecimento. São Paulo: Saraiva, 2003.

CHAVES, Francisco Eduardo C. Controle externo da gestão pública. Niterói: Impetus, 2007. 
CRESWELL, J. Projeto de pesquisa: métodos qualitativo, quantitativo e misto. 2. ed. Porto Alegre: Artmed; Bookman, 2007.

JUND, Sérgio. Administração, orçamento e contabilidade pública: teoria e questões: estilo ESAF, UnB e outras bancas examinadoras. Rio de Janeiro: Elsevier, 2006.

KAUZES, James M.; POSNER, Barry Z. O desafio da liderança. 3 ed. São Paulo: Campus; Elsevier, 2003.

MINTZBERG, Henry; BRIAN QUINN, James. O processo da estratégia. Porto Alegre: Bookman, 2001.

MINTZBERG, Henry; AHLSTRAND, Bruce; LAMPEL, Joseph. Safári de estratégia: um roteiro pela selva do planejamento estratégico. Porto Alegre: Bookland, 2000.

MOREIRA, M. A. Modelos mentais. Investigações em Ensino de Ciências, Porto Alegre, v. 1, n. 3, p. 193-232, dez. 1996.

OLIVEIRA, Djalma de P. R. de. Planejamento estratégico: conceitos, metodologia e práticas. 22. ed. 2. reimp. São Paulo: Atlas, 2006.

RONDONIA. Tribunal de Justiça do Estado de Rondonia. Planejamento estratégico. Porto Velho, 2007. Disponível em: <www.tj.ro.gov.br>. Acesso em: 21 nov. 2008.

SENGE, Peter M. A quinta disciplina: arte e prática da organização que aprende. 23. ed. Rio de Janeiro: BestSeller, 2008.

SOUSA, Célia Maria S. G. de; MOREIRA, Marco A. A causalidade piagentiana e os modelos mentais: explicações sobre o funcionamento do giroscópio. Revista Brasileira de Ensino de Física, São Paulo, v. 22, n. 2, p. 223-231, jun. 2000.

TÔRRES, José Júlio Martins. Teoria da complexidade: uma nova visão de mundo para a estratégia. SUFFRAGIUM: revista do Tribunal Regional Eleitoral do Ceará, Fortaleza, v. 1, n. 1, p. 1-174, set./dez. 2005. 


\section{Para publicar na revista Universitas Gestão e TI, entre no endereço eletrônico www.publicacoesacademicas.uniceub.br. Observe as normas de publicação, facilitando e agilizando o trabalho de edição.}

